\title{
Hemangioma racemoso de retina (síndrome de Wyburn-Mason) - acompanhamento de um paciente por dez anos: relato de caso
}

\author{
Retinal racemose hemangioma (Wyburn-Mason syndrome) - \\ a patient ten years follow-up: case report
}

Leitão Guerra RL ${ }^{1}$

Leitão Guerra $\mathrm{CL}^{2}$

Guerra $\mathbf{M}^{3}$

Guerra Neto $\mathrm{AS}^{4}$

Leitão Guerra $\mathrm{AA}^{\mathbf{5}}$

\section{RESUMO}

Relatar o caso de um paciente que apresentou hemangioma racemoso de retina (síndrome de Wyburn-Mason) e seu acompanhamento por 10 anos. Dez anos após o diagnóstico da doença o exame oftalmológico não sofreu alterações, assim como o campo visual e a retinografia. $\mathrm{O}$ prognóstico a longo prazo é controverso. Alguns autores relatam estabilidade das lesões oculares, como no caso descrito, enquanto outros referem perda progressiva da visão.

Descritores: Angiomatose; Retina/anormalidades; Malformações arteriovenosas/diagnóstico; Síndrome; Relatos de casos [Tipo de publicação]

\section{INTRODUÇÃO}

A síndrome de Wyburn-Mason é uma doença congênita rara que não possui muitos relatos na literatura e que tem um amplo espectro de apresentações ${ }^{(1-2)}$. Trata-se da presença de malformações arteriovenosas localizadas principalmente na retina e no mesencéfalo, porém que podem ocorrer na pele (região inervada pelo trigêmeo), nos anexos oculares, em outras regiões intracranianas, na mandíbula, na maxila, no palato e nas cavidades oral e nasal ${ }^{(1)}$.

Seus sinais e sintomas são muito diversificados e têm relação direta com o local da alteração vascular e sua extensão ${ }^{(3-4)}$.

Macroscopicamente, a lesão retiniana caracteriza-se por uma ou mais anastomoses de vasos muito dilatados e tortuosos, sendo impossível diferenciar artérias e veias ${ }^{(1)}$. Estas malformações originam-se de uma disgenesia vascular do plexo embriológico anterior no início do período gestacional, quando o mesoderma vascular é partilhado por todas as estruturas envolvidas $^{(5)}$.

Este artigo visa relatar o caso de um paciente que apresentou hemangioma racemoso unilateral na retina e seu acompanhamento por 10 anos.

Endereço para correspondência: Ricardo Leitão Guer-

ra. Rua Catarina Paraguaçu, 8 - Salvador (BA)

CEP 40150-200

E-mail: ricardo@leitaoguerra.com.br

Recebido para publicação em 17.08.2008

Última versão recebida em 28.01.2009

Aprovação em 21.05.2009

Nota Editorial: Depois de concluída a análise do artigo sob sigilo editorial e com a anuência do Dr. João Borges Fortes Filho sobre a divulgação de seu nome como revisor, agradecemos sua participação neste processo.

Os autores declaram não haver interesse financeiro em nenhum produto utilizado.

\section{RELATO DO CASO}

Paciente do sexo masculino, 25 anos, natural de Salvador - BA, submetido a exame oftalmológico de rotina em 1997, sem queixas. Não apresentava dados relevantes nos antecedentes médico e familiar.

Ao exame oftalmológico apresentava acuidade visual (AV) de 20/20 parcial sem correção, exame externo e biomicroscopia sem alteração em ambos os olhos (AO) e, ao mapeamento de retina, apresentava exame normal 
no olho direito (OD) e grande dilatação de alguns vasos retinianos com nítidas comunicações arteriovenosas no olho esquerdo $(\mathrm{OE})$. O exame neurológico não demonstrou nenhum achado significativo.

Foi realizado campo visual (CV) que se apresentou sem alterações em AO. A retinografia (Figura 1A) confirmava os achados da fundoscopia indireta e a angiofluoresceinografia (Figuras $1 \mathrm{~B}$ e 2A) apresentava exame normal no OD e, no OE apresentou tempo circulatório normal, grandes vasos dilatados, comunicações arteriovenosas mais acentuadas no quadrante temporal superior e comunicações arteriovenosas peripapilares.

Após o diagnóstico, o paciente recusou-se a realizar investigação para malformações vasculares na região encefálica e optou por conduta expectante, sendo avaliado periodicamente.

Dez anos após diagnóstico, o paciente apresentava AV de 20/25 sem correção em AO, exames biomicroscópico e fundoscópico mantidos. Foram realizados novo $\mathrm{CV}$, que não apresen- tou alterações, e nova retinografia (Figura 2B) que não demonstrou evolução das alterações vasculares no OE.

\section{DISCUSSÃO}

A síndrome de Wyburn-Mason possui amplo espectro de apresentação ${ }^{(1,3-4)}$, não sendo, portanto, obrigatória a presença de todos os seus elementos para caracterizá-la ${ }^{(1)}$.

A presença de alterações vasculares características (hemangioma racemoso) na retina torna mandatória a busca por lesões intracranianas de mesma natureza, uma vez que existe relação direta da extensão do comprometimento retiniano e a probabilidade de lesões vasculares intracranianas. Cerca de $90 \%$ dos pacientes com acometimento grave na retina e consequente baixa AV apresentam também lesões vasculares no sistema nervoso central $^{(3)}$.
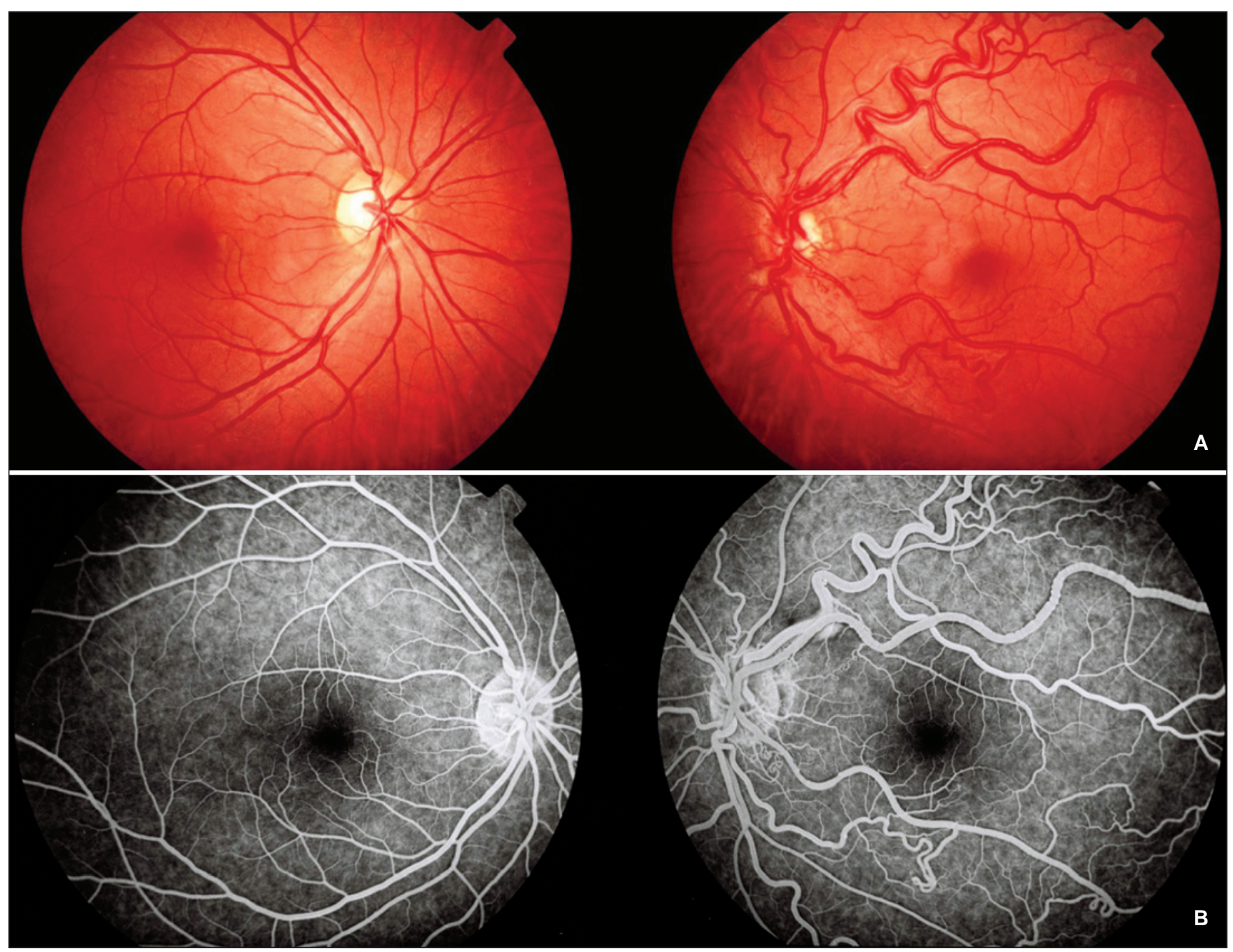

Figura 1 - A) Retinografia normal no olho direito e olho esquerdo apresentando grande dilatação de vasos retinianos, aumento da tortuosidade e nítidas comunicações arteriovenosas; B) Angiofluoresceinografia normal no olho direito e evidenciando dilatação de grandes vasos com aumento da tortuosidade e comunicações arteriovenosas peripapilares no olho esquerdo 


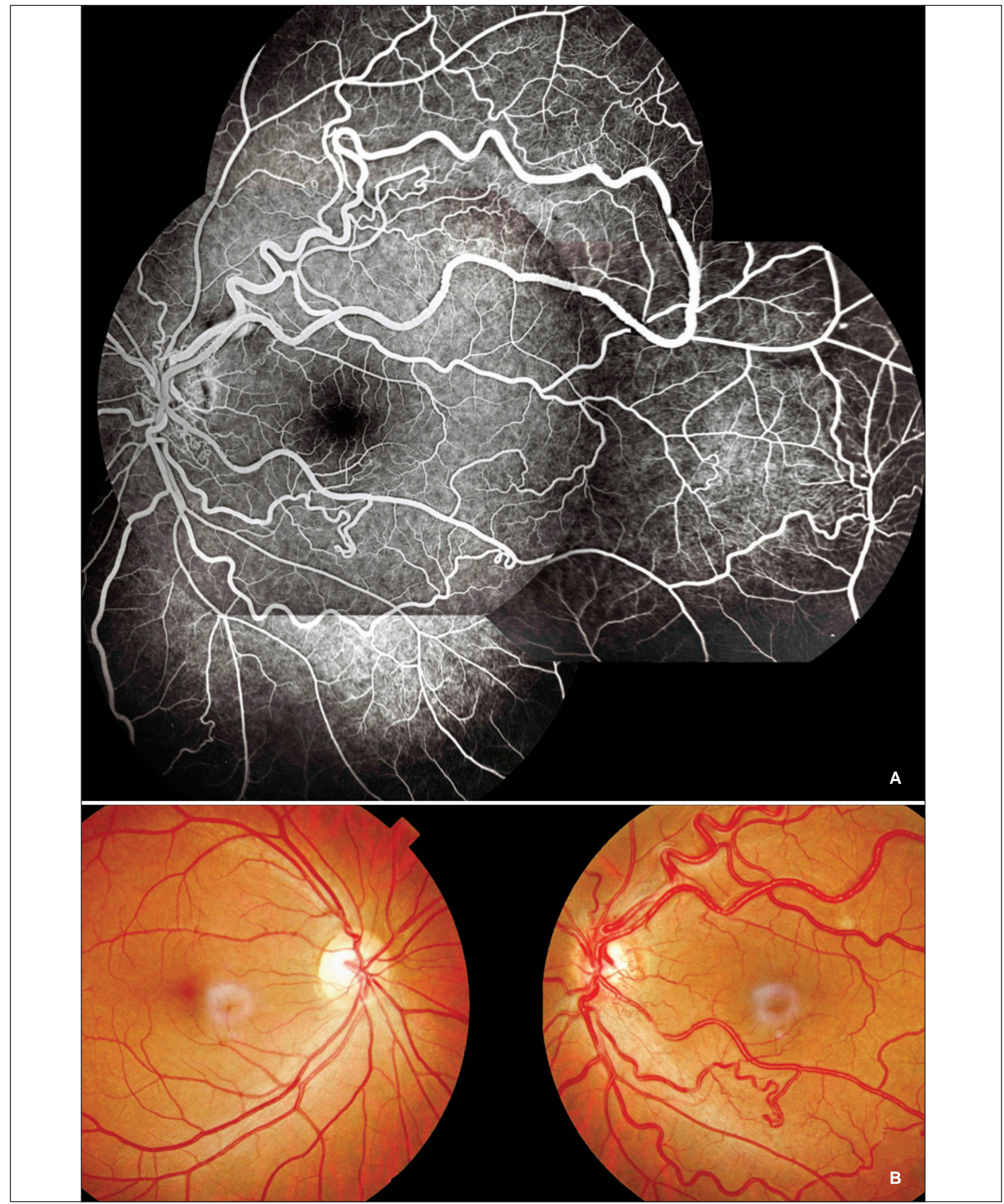

Figura 2 - A) Montagem angiofluoresceinográfica do olho esquerdo (fase arteriovenosa) evidenciando comunicações arteriovenosas; B) Retinografia dez anos após o diagnóstico (caráter estável das malformações vasculares no olho esquerdo, sem evidências de progressão da doença) 
No caso relatado a AV era 20/25 sem correção, o campo visual normal e não havia queixas de visuais ou neurológicas. No caso descrito, o paciente negou-se a realizar a investigação neurológica.

Outros sinais típicos da síndrome estavam ausentes no paciente descrito: proptose (decorrente de crescimento de veias orbitárias em torno do nervo óptico); qualquer achado dermatológico na face (que ocorrem principalmente na região inervada pelo trigêmeo e fazem parte da descrição inicial da doença por Bonnet-Dechaume-Blanc); e por fim achados neurológicos (que podem variar de acordo com a área e extensão da lesão) $)^{(3)}$.

O prognóstico, a longo prazo, desses casos é controverso. Alguns autores relatam estabilidade das lesões oculares em acompanhamentos de até 12 anos enquanto outros referem perda progressiva da visão com o passar do tempo ${ }^{(6)}$. Não houve alteração significativa na $\mathrm{AV}$ e no $\mathrm{CV}$ do paciente descrito durante o longo período do seguimento. Não há um tratamento oftalmológico específico para essa condição e o tratamento neurológico pode ser feito por ressecção cirúrgica da lesão encefálica (com a possibilidade de sequelas pós-operatórias), radioterapia (uso restrito por possuir grande risco de lesão hipotalamo-hipofisária) e embolização via catéter (com bons resultados em casos específicos). Entretanto na maioria dos casos, devido à relação risco/benefício, a conduta adotada é expectante - como no descrito.

\section{ABSTRACT}

To describe the case of a patient who presents retinal racemose hemangioma (Wyburn-Mason syndrome) and his 10 years follow-up. Ten years after the disease diagnosis, the ophthalmologic exam had no changes, as well as the campimetry and the retinography. The long term prognosis is controversial. Some authors report ocular lesions stability and others report progressive visual loss.

Keywords: Angiomatosis; Retina/abnormalities; Arteriovenous malformations/diagnosis; Syndrome; Case reports [Publication type]

\section{REFERÊNCIAS}

1. Bastos AM, Lobão CAF, Jesus ITS, Pantoja AJM. Malformação vascular retinoencefálica, síndrome de Wyburn-Mason: relato de caso. J Bras Neurocir. 2002;13(3):101-5.

2. Jain IS, Sharma SK, Dhir SP, Kaul RL. Wyburn-Mason syndrome (a case report). Indian J Ophthalmol. 1980;28(3):161-3.

3. Ferry AP. Other phakomatoses. In: Ryan SJ, editor. Retina: basic science and inherited retinal disease. $3^{\text {rd }}$ ed. St. Louis: Mosby; 2001. p.600-2. v.1.

4. Dayani PN, Sadun AA. A case report of Wyburn-Mason syndrome and review of the literature. Neuroradiology. 2007;49(5):445-56

5. Ponce FA, Han PP, Spetzler RF, Canady A, Feiz-Erfan I. Associated arteriovenous malformation of the orbit and brain: a case of Wyburn-Mason syndrome without retinal involvement. Case report. J Neurosurg. 2001;95(2):346-9.

6. Reck SD, Zacks DN, Eibschitz-Tsimhoni M. Retinal and intracranial arteriovenous malformations: Wyburn-Mason syndrome. J Neuroophthalmol. 2005;25(3):205-8 